\title{
EL DERECHO DEL NIÑO A SER OÍDO EN LA JUSTICIA DE FAMILIA: LA ESENCIALIDAD DEL DERECHO VERSUS LA ESENCIALIDAD DEL TRÁMITE DE LA AUDIENCIA CONFIDENCIAL
}

\author{
THE RIGHT OF THE CHILD TO BE HEARD IN FAMILY JUSTICE: THE \\ ESSENTIALITY VERSUS THE ESSENTIALITY OF THE CONFIDENTIAL \\ HEARING PROCESS.
}

\author{
Francesco Carretta Muñoz*
}

\begin{abstract}
RESUMEN: Se examina el derecho del niño a ser oído desde una perspectiva procesal en la justicia de familia. En esa área, una de las interrogantes que surge a propósito de la actuación donde se ejecuta el Derecho, es si este constituye un trámite esencial en los términos establecidos en la ley para hacer procedente el recurso de casación. Según la Corte Suprema chilena es así, al contrario de lo que sostiene este estudio.
\end{abstract}

Palabras clave: Procedimiento de familia, derecho del niño a ser oído, recurso de casación.

ABSTRACT: It examines the right of the child to be heard from a procedural perspective in family justice. In this area, one of the questions that arises about the action where this right is executed is whether it constitutes an essential procedure in the terms established in the law to allow the appeal of cassation. According to the Chilean Supreme Court, contrary to what this study holds, it is so.

Keywords: Family procedure, the right of the child to be heard, cassation.

\section{INTRODUCCIÓN}

El derecho del niño a ser oído fue incorporado en el ordenamiento jurídico nacional hace 27 años, con la suscripción por el Estado chileno de la Convención sobre los derechos del niño. Desde ahí se consagra como un derecho humano que se encuentra establecido en a lo menos cinco cuerpos legales.

Recientemente la Excelentísima Corte Suprema de Justicia dictó una sentencia cuya doctrina señala que el trámite procesal donde se vierte el derecho en estudio es uno esencial, en los términos del numeral noveno del artículo 768 del Código de Procedimiento Civil. Desde ahí nace la hipótesis principal que motiva esta investigación, distinta a lo que

Doctor en derecho, profesor agregado de Derecho Procesal Civil de la Pontificia Universidad Católica de Valparaíso. Dirección postal: Facultad de Derecho, Pontificia Universidad Católica de Valparaíso, Casilla 4055, Valparaíso, Chile. Dirección electrónica: francesco.carretta@pucv.cl. El autor agradece a Nel Greeven y Romy Rutherford por su ayuda para la elaboración de este trabajo. 
afirma el máximo tribunal y las opiniones de las Cortes que se han uniformado en torno a ella. Se sostendrá en este estudio que la audiencia confidencial del niño, de acuerdo con la ley, no reviste dicho carácter -esencial- y no calza, por lo tanto, en la horma de la mencionada disposición legal. Sucede que el máximo tribunal no ha considerado una serie de aspectos jurídicos y fácticos que se deben tener en cuenta para la habilitación de la diligencia. Aquellos factores serán analizados a través de esta prospección, para fundamentar la tesis que se estima correcta.

La importancia práctica del tópico radica en que actualmente se ha comenzado a usar el recurso de casación en la forma, incluso de oficio, para indiscriminadamente anular juicios en los que el juez no escucha a un niño. Incluso en los casos donde hace uso fundado de su facultad legal de no hacerlo.

Con lo anterior no se está afirmando que el recurso de casación en la forma no es procedente en ninguna circunstancia. Se está postulando, como hipótesis subordinada, que teóricamente su utilización pudiera restringirse solamente al evento en que el juez sin motivo alguno no escucha a un niño, en las causas donde se le presenta esa posibilidad. Pero en tal circunstancia, ha de estimarse que existe más bien una especie de falta de fundamentación de la sentencia y no la carencia de un trámite esencial. Aunque, por los inconvenientes de aquel razonamiento, lo ideal siempre será, frente a la omisión, la interposición de un recurso ordinario de apelación.

Para tratar de corroborar la teoría planteada, se esbozarán los límites jurídicos del instituto mediante la descripción del derecho vigente y la jurisprudencia comprometida en la cuestión. Así como se explorarán algunos aspectos de hecho que sirven para autorizar la procedencia de la audiencia reservada.

\section{ANÁLISIS NORMATIVO}

\subsection{DesCripCión DE LAS NORMAS EN JUEGO}

Las reglas que se refieren al ejercicio del Derecho en referencia se encuentran en seis cuerpos normativos: la ley de matrimonio civil, la ley sobre adopción, la ley que autoriza el cambio de nombres y apellidos, la ley de tribunales de familia (en adelante LTF), y el Código Civil ${ }^{1}$. De todas ellas, el marco referencial lo constituye la Convención de derechos del niño (en adelante CDN). Específicamente lo que señala el artículo $12^{2}$ de dicho tratado internacional. A ella, debe agregarse la Observación General número 12 del Comité de Derechos del Niño de Naciones Unidas, que dota su enunciado de contornos más operativos. Sobre la base de dichos instrumentos internacionales ${ }^{3}$, se establecen los parámetros

\footnotetext{
Artículos 225-2 f, 227, 229 y 242 del Código Civil. Los cuales se refieren a los derechos y obligaciones entre padres e hijos.

2 Es tal la importancia del derecho que es referenciado como uno de los valores fundamentales de la Convención, junto con el derecho a la no discriminación, el derecho a la vida y el interés superior. Véase: NACIONES UnIDAS (2009) p. 5.

3 En la comunidad europea también rige el Convenio Europeo sobre el Ejercicio de los Derechos de los Niños, hecho en Estrasburgo el 25 de enero de 1996. La importancia de este instrumento radica que a partir de él se habla del niño como un sujeto procesal y más que ello, dado lo detallada que resultan sus normas, en con-
} 
siguientes: (i) que existan garantías por parte de los Estados para la práctica de la diligencia. Con esto, existe la obligación estatal de incorporar mecanismos adecuados para que el niño sea escuchadó. (ii) Que el niño de que se trate, para que pueda declarar, esté en condiciones de formarse un juicio propio, lo que implica que no se puede partir de la premisa que un niño es incapaz de expresar su opinión y siempre se deberá evaluar su capacidad de formarse una opinión autónoma. Además, han de considerarse las formas no verbales de expresión, tales como dibujos, expresiones faciales, etc. Finalmente, la posibilidad que se expresen los niños con discapacidad o pertenecientes a minorías étnicas 5 . (iii) Que este pueda expresar su opinión libremente en todos los asuntos que le afecten. Ello significa que su declaración no sea sujeta a ninguna presión, ni manipulación, por parte de terceros ${ }^{6}$. Y que, (iv) sus opiniones sean tomadas en cuenta en función de su edad y madurez. Es decir, no basta con escucharlo, sino que deben tomarse en consideración sus opiniones de acuerdo con dichos factores. En ese sentido, como la edad y madurez son aspectos relativos, sus declaraciones deben analizarse caso a caso, sin límites predeterminados ${ }^{7}$. Luego, como una forma de asegurar el derecho, debe dársele la oportunidad de ser escuchado en todo procedimiento, directamente o por medio de un representante. En su expresión final, la CDN busca encuadrar todo lo anterior en la ley procedimental nacional donde se inserte. Con ello la norma no se autorregula, sino que descansa en el rito que cada ordenamiento jurídico tenga previsto para estos efectos.

En Chile la CDN es anterior a casi todos los cuerpos normativos donde el derecho se reglamenta. De acuerdo con ello, se deduce que los cuatro patrones vistos, se vierten sucesivamente de una u otra forma en el sistema legal, como se verá continuación.

Así, en el artículo 16 de la ley de tribunales de familia se anuncia como un principio rector que el juez debe tener como consideración principal para resolver un asunto. La dificultad que ofrece la norma se encuentra en el amplio espectro de posibilidades de interpretación y aplicación que ofrece como un principio jurídico ${ }^{8}$.

El artículo 69 de la misma ley precisa que en las causas sobre medidas de protección se faculta al juez a escuchar a los niños, y repitiendo los factores usados en la CDN, en cuanto solo podrá hacerlo en función de su "edad y madurez". El tenor de la norma deja claro que se trata de una elección y no imposición para el magistrado, en tanto usa el vocablo "podrá". A su vez, el artículo 79 del citado cuerpo legal, consagra una situación para

ferirle una acabada operatividad a sus derechos en la tramitación de un procedimiento, a tal punto que puede estimarse como una parte, en sentido adjetivo. MAGNO (2001) p. 4.

4 Naciones Unidas (2009) p. 9.

5 NaCiones Unidas (2009) p. 10.

6 Naciones Unidas (2009) p. 10.

7 NACIONES Unidas (2009) p. 11.

8 Las complicaciones que se acostumbra a citar por la doctrina son básicamente tres. Primero, que la formulación de un principio jurídico suele ser ambigua, hay un notable problema terminológico. Por ejemplo, se alude a ellos como sinónimos de normas, directrices morales o reglas. Luego, son imprecisos, es decir, no hay certeza sobre su contenido. En este rumbo, se suele mencionar que son demasiado generales. No hay claridad ni acuerdo sobre cuáles son y cuáles son sus alcances. En tercer lugar, su falta de contenido tangible, por una parte, hace imprecisa su utilidad práctica, y por la otra, los conecta con facilidad al sentido común del sujeto. Sobre el particular véase: SCHAuer (1991) pp. 19-24; LuZzati (2012) pp. 4-5; Guastini (2013) pp. 34 -36. 
la que, en realidad era innecesaria la norma: el derecho para los niños, al que subyace la obligación para el juez, de ser escuchados siempre que ellos lo requieran. La ley parece decir que solo en los procedimientos por medidas de protección puede ejercerse este derecho; pero aquello no es así, desde que la misma Convención no le pone trabas al libre ejercicio del imperativo y lo plantea en términos amplios ${ }^{9}$. En ese orden de ideas, el niño puede manifestar lo que le sea conveniente en cualquier momento del proceso donde su interés esté involucrado. Esto debe relacionarse con el hecho que la legislación chilena contiene una amplia tutela cautelar ${ }^{10}$, que puede gestarse incluso antes de comenzar el procedimiento ${ }^{11}$.

Finalmente, este derecho está consagrado como uno de los principios de la mediación, en términos singulares y más estrictos que los otros apartados. Se puede citar al niño solo si su presencia es "estrictamente indispensable para el desarrollo de la mediación"12. Probablemente, los legisladores tomaron en cuenta dicha precaución teniendo presente que la mediación -aun cuando en muchos casos es obligatoria- no constituye propiamente una instancia jurisdiccional.

La ley de matrimonio civil ${ }^{13}$, en las disposiciones referidas a los juicios de separación, nulidad y divorcio transita por un camino similar a la LTF. En ella específica que el juez oirá a quién esté en "condiciones de formarse un juicio propio". Reiterando que aquello debe ser analizado en función de su "edad y madurez".

Frente a todas las normas citadas ${ }^{14}$ que poseen, como se señaló, medidas similares y como hilo conductor una facultad para el juez, irrumpe la ley n. ${ }^{\circ} 19.620$. Su artículo tercero impone al sentenciador, cuando se trata de un menor adulto, en las causas por susceptibilidad de adopción y adopción ${ }^{15}$, pesquisar siempre su consentimiento; ya sea con relación a la posibilidad de ser adoptado, en el primer caso, o de serlo en forma efectiva por perso-

Artículo 12 de la Convención: “1. Los Estados partes garantizarán al niño que esté en condiciones de formarse un juicio propio del derecho a expresar su opinión libremente en todos los asuntos que afecten al niño, teniéndose debidamente en cuenta las opiniones del niño, en función de la edad y madurez del niño. - 2. Con tal fin, se dará en particular al niño la oportunidad de ser escuchado en todo procedimiento judicial o administrativo que afecte al niño, ya sea directamente o por medio de un representante o de un órgano apropiado, en consonancia con las normas de procedimientos de la ley nacional".

10 Véase el artículo 22 de la Ley $\mathrm{N}^{\circ} 19.968$ de 2004.

11 Sucedió en el tribunal de familia de Valparaíso que dos hermanos de 8 y 12 años concurrieron personalmente a hablar con un juez por la violencia intrafamiliar que se suscitaba entre sus padres. Luego de ser oídos y quedando en evidencia la gravedad de la acusación, aquello motivó la apertura inmediata de un expediente de protección y violencia intrafamiliar. Se citó a los padres a una audiencia preliminar inmediata para la imposición de medidas cautelares, las que, atendido el mérito de los antecedentes fueron adoptadas en beneficio de los niños y la madre.

12 Artículo 105 e) de la Ley No 19.968 de 2004.

13 Artículo 85 de la Ley $N^{\circ} 19.947$ de 2004.

14 A propósito de las leyes citadas, es necesario agregar que la Corte Suprema dictó el año 2014 un auto acordado (acta 237-2014) que regula el ejercicio del derecho del niño a ser oído, mediante la implementación de las "salas Gesell". En dicha normativa se señalan una serie de usos y prácticas que los jueces deben tener en cuenta para la utilización de la mencionada infraestructura.

15 Incluso según la opinión de una autora, la obligatoriedad que impone la norma puede trasladarse a los asuntos de filiación, cuando lo que se afecta en un adolescente es su derecho a la identidad y estado civil, tratándose de acciones de impugnación. Véase: GreEven (2017) pp. 569 - 576. 
nas determinadas, en el segundo ${ }^{16}$. Nótese que la norma no requiere la opinión del niño, sino que solo su consentimiento, lo que circunscribe la diligencia a un punto específico de manifestación de voluntad del niño.

En el mismo sentido de obligatoriedad, singular resulta la ley n. ${ }^{\circ} 17.344$ sobre cambio de nombres y apellidos ${ }^{17}$. El inciso final de su artículo primero utiliza una nomenclatura propia de las leyes referentes a la infancia, anteriores a la incorporación de la CDN al ordenamiento jurídico nacional. Ella se trata de aquellos "menores" que no cuentan con representantes legales o que estos, si los tuviesen, se negaren a autorizar el cambio de nombre que solicitó alguno de sus consanguíneos. Si aquello ocurre, el juez resuelve con audiencia del niño y escuchando al "defensor de menores" o de oficio.

De todas maneras, es importante tener presente que la cantidad de expedientes de adopción y cambio de nombre en un tribunal de familia, son muy inferiores en número a las demás causas que se hallan dentro del amplio abanico de materias que se tramitan habitualmente en dichos juzgados ${ }^{18}$.

\subsection{CONTENido de las nORMAS: LA COMPleja DETERMinACiÓN DE UN FACTOR BINARIO}

Como se dijo al inicio del párrafo anterior, el patrón común a todas las normas señaladas tiene como fuente el artículo doce de la CDN. Entonces, lo que se pueda predicar sobre ella, se puede hacer extensivo a las demás leyes que le son tributarias. Es por lo anterior que se transcribirá y analizará a continuación: "Los Estados Parte garantizarán al niño que esté en condiciones de formarse un juicio propio el derecho de expresar su opinión libremente en todos los asuntos que afectan al niño, teniéndose debidamente en cuenta las opiniones del niño, en función de la edad y madurez del niño." Como se observa, la norma establece específicamente que debe escucharse a todo niño que esté en condiciones de "formarse un juicio propio". En consecuencia, aquel que no posea dicha habilidad no debería ser oído. Luego, la misma norma impone al juez el deber de tomar en cuenta su opinión, pero en proporción a su "edad y madurez". Estas cualidades son, para el contexto literal de la norma, sinónimas. Ello, porque sería un contrasentido estimar que un niño puede formarse un juicio propio y que a la vez no tenga la edad suficiente para opinar, o la madurez para ello.

Pero, más allá de aquel aspecto semántico, la alternativa de oír a un niño confronta circunstancias de hecho de difícil determinación. En efecto, se entiende que no será una labor simple para un magistrado valorar aquellos dos factores evolutivos propios del ser humano $^{19}$, a pesar de contar con un órgano técnico que le asesora. Seguidamente, la función judicial se complejiza más si, como argumentan algunos autores, el juez además debe

\footnotetext{
${ }_{16}$ En todo caso, este consentimiento puede no tomarse en cuenta por el juez fundadamente en mérito de su interés superior.

17 Esta ley data del año 1970.

18 Por ejemplo, el año 2013 se tramitaron en Chile 2.027 causas por adopción, 70.086 por medidas de protección y 84.559 por violencia intrafamiliar. Véase: Anuario estadístico sobre la justicia de familia, Ministerio de Justicia (2013).

19 SÁNCHEZ (2011) p. 60.
} 
establecer una relación simétrica y colaborativa con el niño ${ }^{20}$. Cuestión que no es una mera recomendación. Es el propio sistema legal actual de familia que le otorga el deber al juez y la facultad al niño de contribuir en la construcción del caso ${ }^{21}$, para la adecuada tutela de los intereses que le han sido conculcados ${ }^{22}$.

Su participación se desenvuelve a través de la llamada "audiencia confidencial", aun cuando también puede fluir mediante otros modelos de participación ${ }^{23}$. Lo anterior se desprende del mandato que establece el numeral dos del artículo doce ya citado: "Con tal fin, se dará en particular al niño oportunidad de ser escuchado en todo procedimiento judicial o administrativo que afecte al niño, ya sea directamente o por medio de un representante o de un órgano apropiado, en consonancia con las normas de procedimiento de la ley nacional”. Es interesante notar que la disposición no establece ninguna exigencia sobre la estructura y localización de la audiencia ${ }^{24}$. A pesar de ello, el legislador chileno (artículo 69 de la LTF) dice que esta debe realizarse en "un ambiente adecuado y cautelando su salud física y psíquica". En cumplimiento de tal mandato, en algunos tribunales del país se han habilitado salas especiales denominadas "Gesell” que cumplen con los requerimientos necesarios para crear dicho ambiente ${ }^{25}$, con la finalidad de que el niño pueda manifestar su opinión sin contratiempos ${ }^{26}$. Trámite que no está exento de polémica. Sobre el particular hay doctrina que justificadamente ejerce un cuestionamiento ${ }^{27}$. Este se fundamenta en dos circunstancias. Una, es que los jueces no permiten la presencia de los abogados durante la audiencia, conculcándose así su derecho de defensa. La otra, es que no consignan en sus sentencias lo que escucharon decir de los niños, afectándose de esta manera su derecho a recurrir $^{28}$.

En suma, los aspectos para tener en cuenta en la diligencia en comento -edad y madurez- corresponden a dos factores complejos que, para habilitar el trámite, deben ser previamente valorados por el juez. En otras palabras, el juez no tiene la obligación de escuchar a un niño en todas las causas donde puedan verse afectados sus derechos. Es una valoración privativa que debe ser comprendida con ciertos matices. Ello, porque de ninguna manera le está permitido al juez a su entero capricho oír o no al niño. Por el contrario, lo que aquí se sostiene es que este derecho será coartado si el juez procede con arbitrariedad. Eso ocurre 
cuando no expone las razones para proceder de tal manera o bien, exponiéndolas no tome en cuenta las condiciones antes dichas.

Por lo tanto, una de las garantías del derecho, en los términos establecidos en la Convención, es el deber judicial de expresar los argumentos a través de los cuales se hizo o no uso de la elección que permite el ordenamiento jurídico. Justificación que va más allá del deber general de fundamentación de toda resolución judicial ${ }^{29}$.

Por último, todo lo señalado en este acápite llama a una reflexión útil para el tema central de este estudio: ¿puede un tribunal de grado valorar con claridad los complicados aspectos fácticos que habilitan la práctica de la audiencia confidencial, como para apreciar las razones por las que el juez de la instancia decidió no escuchar a un infante?

\section{FORMA VERSUS FONDO. LA ESENCIALIDAD DEL DERECHO VERSUS LA ESENCIALIDAD DEL TRÁMITE DONDE EL DERECHO SE CONTIENE}

Antes de analizar lo decidido por los tribunales de justicia, en necesario tener en cuenta que el derecho del niño a ser oído (en adelante DNO) a primera vista pudiese presentarse con una impronta de fragilidad frente a los operadores, que muchos se pueden sentir tentados a defender a ultranza. Algo así como una propensión natural que conduce a proteger al más débil. Traduciéndolo al lenguaje procedimental, puede que los magistrados con todas sus buenas intenciones y preparación, seducidos por su instinto canalicen inadecuadamente la tutela de este derecho. Sobre todo, si para su debida protección se debe actuar con prontitud. En este orden de ideas, la cuestión o confusión que el presente estudio quiere dejar entrever se cierne sobre el siguiente contexto. Coloquialmente, que el derecho del niño a ser oído sea de vital importancia, como se dijo en la introducción, o "esencial" en el sentido común, es evidente. Pero esa virtud no necesariamente se traslada con los mismos contornos a la esencialidad en sentido procesal. El primero se encuadra en la sustancialidad del derecho, en la cualidad inherente del ser humano que le confiere la capacidad de expresarse en los asuntos que le atañen. Mayormente aquellos sujetos que se encuentran en grupos vulnerables como los niños. El segundo, en cambio, no alude a un sujeto, sino a un objeto, o más bien a un instrumento, cuyo fin es servir al derecho sustantivo. En este punto vale la pena recordar la distinción entre la sustancia y la forma adjetiva, ${ }^{30}$ pues el

\footnotetext{
29 En el sentido anotado se pronuncia el fallo Atala dictado por la Corte Interamericana: "Sin embargo, el hecho de que una autoridad judicial no tenga que recabar nuevamente el testimonio a un niño o niña en el marco de un proceso judicial, no la libera de la obligación de tener debidamente en cuenta y valorar, en un sentido u otro, las opiniones expresadas por la niña y el niño en las instancias inferiores, en función de la edad y capacidad del niño. De ser pertinente, la autoridad judicial respectiva debe argumentar específicamente por qué no va a tomar en cuenta la opción del niño o la niña." CORTE IDH. Caso Atala Riffo e hijas vs. Chile. Fondo, reparaciones y costas. Sentencia de 24 de febrero de 2012. Serie C No. 239, disponible en: http://corteidh.or.cr/ docs/casos/articulos/seriec_239_esp.pdf

30 La calificación de "adjetiva" obedece a que las formas revisten diversos significados en el ordenamiento jurídico. Para este trabajo se hace sinónima de "forma procesal”. Véase: Negri (1962) pp. 2-3; BelVEdere (1994) pp. 148 -158; Thomas (2005) pp. 55-56.
} 
proceso está construido sobre formas adjetivas ${ }^{31}$. Estas son el envoltorio de los actos procesales $^{32}$. Una garantía del fair play en la contienda de las partes ${ }^{33}$ y a la vez aseguran la imparcialidad del Juez ${ }^{34}$. Estas virtudes en su totalidad se infunden a la función pública de administrar justicia ${ }^{35}$. Al contrario, su carencia, conlleva caos y sospecha ${ }^{36}$. De acuerdo con ello, los vértices del proceso, absolutamente delimitados y cuantificados expresamente, son catalogados como esenciales, pero no por una razón intangible, sino solo por preservar la seguridad jurídica. Son patrones objetivos.

La operación es simple de verificar y aplicar. Si los trámites fundamentales no se cumplen, el ordenamiento ha previsto una sanción específica: la nulidad. No sucede así para la determinación del ejercicio del DNO, el cual está impregnado de condiciones subjetivas, siendo una de ellas: la difícil cualificación de la madurez del menor. Si esa condición no concurre, la ley no previó el mismo efecto establecido para la ausencia de una gestión adjetiva esencial. En realidad, tratándose dicho cometido de una facultad, como se pretende demostrar aquí, el ordenamiento jurídico no estableció ninguna consecuencia. Por ello, no puede haber una transmisión de la cualidad inherente del derecho de fondo al acto procesal donde ese derecho se ejecuta, si una norma no lo dispone expresamente.

Estas reflexiones nacen del análisis jurisprudencial que se efectuará a continuación. En él se advierte poca claridad sobre los límites señalados. Sucede que, al parecer, a la judicatura le resulta difícil pensar que, si el juez no cumplió con el trámite de escucha, aunque dicha omisión sea fundamentada, no razone inmediatamente que el magistrado no cumplió con una tarea esencial en todos los sentidos. Se intentará demostrar en adelante que esto no es así. En esos casos, el exacto calificativo, para poner la cuestión en el cabal contrafuerte jurídico, es que el juez no cumplió con un acto procesal importante, pero estando habilitado por el ordenamiento para no hacerlo.

Si el juez del tribunal revisor comprende que lo esencial en sentido general, es diverso a lo mismo en sentido procesal, entonces no hay problema. No hay en él confusión y encontrará el camino adecuado por las vertientes que el sistema jurídico ofrece para restablecer el Derecho, si estima que el inferior no ejerció bien su facultad. La dificultad se presenta con aquel que confunde la esencialidad del derecho -que dicho sea de paso involucra muchos más aspectos- con la esencialidad del trámite donde yace la sustantividad del derecho. Aquel no encontrará otra vía que la nulidad frente a la omisión de lo que considerará un trámite esencial del proceso, que como sostiene este estudio, no es la solución correcta.

\footnotetext{
31 No se puede confundir con el formalismo procesal, que alude a una excesiva burocracia en los trámites judiciales. Véase: Chiarloni (2013) p. 534; Denti (1982) p. 123.

32 Luiso (2007) p. 400.

33 De alguna manera se quiere significar con esta afirmación que a través de las formas se busca la certeza jurídica como previsibilidad. Pero teniendo en consideración las implicancias que la certeza jurídica, ya sea desde el punto de vista axiológico, como por la ambigüedad del término, reclamada por algunos autores, esta afirmación no puede ser demasiado categórica. GOMETz (2005) passim.

34 Comoglio et al. (2011) p. 320.

35 Monteleone (2009) pp. 290-291.

36 Chiovenda (1965) p. 663.
} 
En ese caso, todo indica que la vital importancia del derecho transmutada al rito, unida a la urgencia de tutela, son las dos premisas que forman el silogismo del que se deduce necesariamente la casación. Pero según se verá en adelante, entre otras cosas, esa postura olvida que por sí misma la casación reviste varios dilemas. Como acertadamente ilustra un autor: "la casación es especialmente problemática" ${ }^{37}$. Con mayor razón si en ella se dirimen derechos humanos fundamentales e instituciones jurídicas modernas.

\section{JURISPRUDENCIA}

Sobre la esencialidad del trámite que se asemeja a la obligatoriedad del mismo, hay una sentencia de la Corte de Apelaciones de Punta Arenas. Esta, para arribar a su decisión, considera lo siguiente: "que, el derecho de los niños a ser oídos, que la ley chilena ha catalogado también de primordial, al igual que su interés superior, es otro tema en el cual el Juez tiene una obligación, por mandato del artículo 16 de la Ley 19.698"38.

También, la Corte de Apelaciones de Valdivia, conoce un proceso cuyo origen trata sobre una madre que se opone a que su hijo de 11 años que padece de cáncer, le sea suministrado un tratamiento de quimioterapia. Esta, prefiere acudir a un método alternativo de curación. El tribunal a quo, vía medida de protección, insiste en que se le efectúe el procedimiento médico tradicional. Al parecer, según el fallo de la Corte, el juez de primera instancia prescindió de la audiencia confidencial para escuchar el parecer del niño ${ }^{39}$. El tribunal de apelación, revoca dicha resolución, fundado en que la audiencia reservada es de carácter obligatoria. De esta manera, la jueza de primera instancia, según lo resuelto, habría infraccionado los artículos 12 de la CDN y el artículo 16 de la LTF.

Un fallo de la Corte de Apelaciones de San Miguel $^{40}$ que se pronuncia sobre una casación en la forma interpuesta por una de las partes, señaló: "Que en esta causa, dar cumplimiento a tal normativa era especialmente relevante, si se considera que se trataba de disponer la forma como debía generarse un régimen comunicacional con un padre ausente por muchos años, todo lo cual provoca en el menor un importante grado de ansiedad, según se deja constancia en uno los informes periciales que la sentenciadora tuvo como elementos de prueba. Escuchar al menor en una materia que es de su directa y total incumbencia, era también posible si se considera que la pericia psicológica da cuenta que tiene un desarrollo físico y maduracional propio del ciclo vital en que se encuentra, su desarrollo de lenguaje es apropiado y tiene la capacidad de comprender y expresar ideas de forma clara y fluida. Se daban así las condiciones necesarias para cumplir con tal esencial diligencia, cuyo resultado es determinante al momento de decidir si el derecho que el padre quiere ejercitar debe prevaler sobre el interés superior del menor, que según el artículo $3^{\circ}$ de la Convención ya citada, debe tenerse en cuenta como una consideración primordial. Al no haberse proce-

37 Excede las líneas de este estudio abordar todas las incógnitas que presenta la casación. De todas maneras, aparte de los otros artículos citados en este estudio, véase con especial atención el análisis de Fernando Atria que explora aspectos singulares sobre la institución. AtRiA (2005) pp. 249 -351.

38 R. I. M C. y R. N. M. C. (2011).

39 R. L. G. N. (2009).

40 L. CON S. (2011). 
dido de la manera dicha, se ha faltado a una diligencia, cuyo carácter esencial es incuestionable, siendo la única forma de reparar tal omisión la anulación de la sentencia y del juicio que le sirve de antecedente, por lo que el recurso de casación, sobre la base de esta causal, será acogido".

En un sentido opuesto existe una sentencia de la Corte de Apelaciones de Valparaíso $^{41}$ que no dio lugar a la casación formal fundada en la misma causal del fallo anterior, porque consideró que la edad de una niña -4 años- no hacía necesaria la práctica de la diligencia. En lo sustancial expuso: "No cabe duda alguna que (...), por su escasa edad, difícilmente estaría en condiciones de formarse un juicio propio con relación al asunto que se ventila en la causa, por lo que si la Jueza no estimó necesaria oírla sería una decisión correcta”. En ambas sentencias, no hay noticia si precedió la necesaria preparación del recurso, teniendo en cuenta que la infracción se produce en el desarrollo del proceso y no en la sentencia.

Todas las sentencias citadas cristalizan en una decisión de la Excelentísima Corte Suprema de Justicia que se transcribe a continuación: "que por otro lado, debe considerarse que conforme a la edad del niño, alrededor de 11 años, este ya goza de un germen de autonomía, que conforme se va desarrollando, va progresivamente consolidándose, la cual debe ser apreciada por los sentenciadores, reafirmando que el deber de otorgar a este la posibilidad de ser oído en la sustanciación de un proceso en que se pretende determinar su identidad, constituye un trámite esencial del procedimiento cuya omisión debió corregir la Corte de Apelaciones de Santiago, de modo que, al no hacerlo se ha configurado la causal de nulidad formal prevista por el artículo 768 n. ${ }^{\circ} 9$ del Código de Procedimiento Civil, en relación con el artículo 800 del mismo cuerpo de normas, texto que, al designar los trámites o diligencias esenciales en segunda instancia, al igual que lo hace el artículo 795 en relación a la primera instancia, utiliza la expresión: «En general» lo que permite entender que la enumeración que en tales textos se contiene, no es taxativa" ${ }^{\text {"2. }}$.

Este fallo luego es aludido por una sentencia reciente que invalida de oficio otra dictada por un tribunal de primera instancia. Esta se pronuncia sobre una disputa de cuidado personal, donde el juez no consultó la opinión del hijo de las partes al minuto de establecer a quién de ellos le correspondía ejercer su tuición ${ }^{43}$. En este tipo de causas es natural que el juez evite preguntar a los hijos con qué padre quiere residir. Ello, porque no se quiere dejar el peso de la responsabilidad de tal decisión en sus manos. Esto no significa que el juez se base únicamente en lo que el niño dijo, pero se tiende a pensar que su inmadurez le impide idear tal responsabilidad. Ciertamente, aquello no es tomado en cuenta, a pesar de que la Corte entra derechamente a la valoración de los antecedentes probatorios vertidos en ella, para decidir por su nulidad.

\footnotetext{
A. CON T. (2012).

42 E. CON D. (2015).

43 M. CON G. (2016).
} 
Desde aquí en adelante, es natural pensar que los tribunales inferiores comiencen a uniformar la jurisprudencia ${ }^{44}$, en torno a la siguiente ratio decidendi: "que el derecho del niño a ser oído es un trámite esencial del procedimiento, en los términos del artículo 768 $\mathrm{n}^{\circ} 9$ del Código de Procedimiento Civil." Sin embargo, dicha doctrina tiene algunas sombras y matices que es bueno dilucidar.

\section{DE ACUERDO CON LA LEY, LA AUDIENCIA CONFIDENCIAL NO ES UN TRÁMITE ESENCIAL DEL PROCESO}

Si se sigue el argumento exegético que utiliza la Corte Suprema para sostener que la casación en la forma en estos casos es posible, entonces a él también se pueden oponer contraargumentaciones concretas y de texto. Ello, porque el vocablo "generalmente" que utiliza al artículo 800 del Código de Procedimiento Civil, parece decir que existen otros trámites o diligencias esenciales. Esta expresión, no puede mirarse a solas y debe ser complementada con su fuente principal. Sucede que la norma matriz no es el artículo 800, sino el numeral noveno del artículo 768 del mismo cuerpo legal. En él se expresa que cualquier trámite o diligencia, para ser considerados como esenciales, deben ser así declarados por la ley o, si la ley no lo dice, debe tratarse de "cualquier otro requisito por cuyo defecto las leyes prevengan expresamente que hay nulidad”. Como se ha venido razonando, dicha esencialidad en sentido procesal no está expresamente establecida para la diligencia sobre la que se ejecuta el DNO.

No obstante, estos fundamentos apegados a la letra de la ley, tanto el uno como el otro, no son suficientes. Entonces, más allá de una elucidación literal, tanto las Cortes citadas, como el máximo Tribunal del país, yerran en la apreciación de la convergencia del DNO, con los aspectos adjetivos primordiales para tener en cuenta. Tradicionalmente, la casación se limita a velar por la correcta observancia de la ley (función nomofiláctica) ${ }^{45}$. En términos simples, a la Corte Suprema no le está permitido la valoración de los hechos de la causa, lo justo o lo injusto. Su función es la fiscalización de la atenta aplicación de la ley por parte de los jueces, del clásico binomio ${ }^{46}$ decisoria litis y, en este caso, las leyes ordenatoria litis $^{47}$. Recordando así la primacía de la ley en un sistema continental como el chileno ${ }^{48}$.

\footnotetext{
44 Aparte de la sentencia citada en el numeral anterior, así consta expresamente en sentencia posterior de la Corte de Apelaciones de Santiago, de fecha 22 de noviembre de 2016 en los siguiente términos: "Seguidamente y por haberse omitido cumplir, en el caso sub judice con el trámite esencial consistente en escuchar al niño (...) en primera instancia como lo ha consignado la Corte Suprema en causa rol no..." G. con P. (2016). En términos similares se ha acogido una casación en la forma en sentencia dictada por la misma Corte. S. O. T. (2016).

45 Romero et al. (2008) pp. 225-259.

46 Romero (2013) pp. $44-47$.

47 Lo refractaria que puede ser la Corte Suprema a dicho fin y las connotaciones y disquisiciones que surgen a propósito de la distinción entre leyes ordenatoria y decisoria litis, sobrepasan en mucho a los fines de esta investigación.

48 Afirmar aquella distinción es discutible y discutido por la doctrina especializada, pero aquí sirve como referencia para significar al lector, la idea que la diligencia de audiencia confidencial del niño es un trámite esencialmente procesal. Véase: NiEva (2010) pp. 47-52.
} 
Precisamente, aludiendo al mismo argumento, los fallos de la Corte Suprema usan regularmente la frase "jueces del fondo", para rechazar aquellos recursos que pretenden transformar esta vía en un análisis del mérito del proceso. No obstante, es discutido por la doctrina si los fines de la casación hoy en día siguen siendo iguales, teniendo en cuenta toda la elaboración sistemática que CALAMANDrei realizó sobre la misma ${ }^{49}$. De cualquier forma, se puede afirmar en general que a la Corte de casación toca la interpretación de la norma en abstracto ${ }^{50}$, aunque generalemente es un problema recurrente, no solo aquí, que intente hacer justicia en un caso concreto ${ }^{51}$.

Pero no se está propugnando en este escrito la abrogación de un sistema que ha encontrado un statu quo que de alguna manera se ha normalizado. Aquel puede denominarse como el clásico modelo de tercera instancia, en contraposición a la casación en sentido estricto, que obedece a los fines (puros) iniciales ${ }^{52}$. Se está señalando un sistema que va más allá de lo acostumbrado. Es un modelo donde la Corte, para el caso que origina esta prospección, conoce los antecedentes que conforman una causa de un modo similar al que lo hacen los tribunales de mérito. En el mismo sentido al que TARUFFO cataloga peyorativamente un sistema de "tercera instancia" 53

Volviendo a las razones de texto, no hay ninguna ley de fondo en el ordenamiento jurídico chileno, incluida la CDN, que obligue al juez a escuchar en todo caso a un niño o se trate de un trámite "que la propia ley declara como esencial o para cuya omisión la ley prevenga expresamente nulidad”. Es una facultad y no podría no serlo si, como se expresó antes, el juez debe analizar al menos dos circunstancias subjetivas para decidir sobre ello. Si el tribunal superior decide que en tal o cual caso resulta obligatorio escuchar al niño, entonces en realidad está juzgando sobre aspectos cuya apreciación para ellos se basa en meras suposiciones. Ello, porque a través de la casación no se tiene acceso directo e inmediato a los elementos a través de los cuales se forjan tales aspectos en el pleito. Sobre todo, en lo relativo a la difícil ponderación de la madurez de un niño como fue analizado supra. Lo anterior es enunciado en la Convención en cuanto señala que no siempre debe efectuarse tal gestión, sino solo en aquellas en que el niño "esté en condiciones de formarse un juicio propio." Lo obligatorio, conforme con lo establecido en la CDN, es que el juez tenga siempre presente la posibilidad de entrevistar al niño. Pero eso no es suficiente, debe así expresarlo en su resolución. Escuchando y valorando lo que el niño dijo o, no haciéndolo, y, primordialmente fundamentando su decisión en uno u otro sentido. Así lo dice también expresamente el artículo 16 de la ley n. ${ }^{\circ} 19.968$ cuando expresa que: "El interés superior

\footnotetext{
49 NieVA (2010) pp. 42-46.

50 Este es un problema que incumbe a varios sistemas continentales que comprenden la casación. El italiano también es un sistema que se apartó de su modelo original. Véase: TARUFFo (2013) pp. 117-139.

51 Detallar la discusión sobre los fines de la casación y de los fines originales de la misma expuestos latamente por Calamandrei dista mucho del enfoque de la presente investigación. Por ello, baste con señalar que aquí precisamente se está pregonando ese enfoque inicial versus lo que se puede observar en la jurisprudencia expuesta. La razón es simple, el modelo chileno no ha sufrido ninguna modificación legal sustancial desde sus orígenes, por lo que mantiene el rigor en cuanto a su misión primigenia, cual es la uniforme interpretación de la ley y el respeto a las normas del procedimiento. Véase: TARUfFo (2005) pp. 145-166.

52 Atria (2005) p. 274.

53 TARuffo (2005) pp. 222- 225.
} 
del niño, niña o adolescente, y su derecho a ser oído, son principios rectores que el juez de familia debe tener siempre como consideración principal en la resolución del asunto sometido a su conocimiento".

\section{LOS REMEDIOS ADECUADOS AL DERECHO VIGENTE Y A LA INMEDIACIÓN}

\subsection{Problemática}

Las razones que puede haber tenido un magistrado para omitir el trámite procesal de la audiencia confidencial, son dos. (i) Mera omisión, lo que se pesquisa mediante un análisis de las actas de las audiencias o la sentencia, donde simplemente no habrá ningún señalamiento acerca de la práctica del acto. Lo mismo ocurre cuando el juez desatiende la manifestación espontánea del niño en expresar su opinión, o su representante lo solicita expresamente y el juez no lo escucha y no hay constancia de las razones por las cuales el juez arribó a tal decisión. (ii) Omisión fundada, donde sí se conocerán las razones por las que el juez procedió de tal o cual forma. En este caso, como ya se argumentó en el acápite anterior, no es posible la casación por cuanto la audiencia reservada no es un trámite esencial del procedimiento. Por ello, el recurso debe ser declarado inadmisible si se funda en esa causal, en el control preventivo que ejerce tribunal ad quem, conforme lo dispone el artículo 778 del Código de enjuiciamiento.

Para la primera hipótesis, la falta se sustenta sobre una secuencia palmaria: la desatención por parte del juez del trámite de escucha, cuyo antecedente incuestionable es, a su vez, la carencia de la exposición de las razones que tuvo para ello ${ }^{54}$. En ese sentido se está frente a una patología de mayor envergadura: la inexistencia de fundamentación que impide el control por parte de los operadores de uno, o el más importante de los elementos que el sentenciador debe tener en cuenta para resolver, en estos casos ${ }^{55}$.

La audiencia reservada, si bien es uno de los varios aspectos que el sentenciador tiene en mente para fundamentar su decisión, la ausencia de exposición de razones para la desatención en este punto, dada su magnitud, abarca todo el espectro de los motivos de la decisión. Cuando efectivamente se escucha del niño, su interés superior divisado en su declaración, hace que todas las razones para el resguardo de sus derechos se apoyen sobre ella. Si esa base sólida no está, toda la edificación que se haga en torno a ella, o cae o se cimenta sobre la arena. Lo anterior es lo que establece la Convención. Su principio rector, el interés superior del niño (en adelante NNA), para evitar quedar desprovisto de concepciones intuitivas o meras generalizaciones ${ }^{56}$, debe precisamente interrelacionarse con los demás derechos en juego y aspectos reales del proceso.

Necesariamente una de las vías para detectar el interés superior del niño es inquirir su opinión ${ }^{57}$. Una supresión hipotética visualiza el riesgo de haber adoptado una decisión

Véase: ACCATino (2003) pp. 9 - 35.

Aliste (2011) p. 392.

Véase: Ravetllat y Pinochet (2015) pp. 915 - 916.

Naciones Unidas (2013) p. 11. 
cuyos alcances, de haberse oído al niño, quizá pueden haber tenido un rumbo distinto. En ese orden de ideas, es fácil advertir que el curso de las cosas para el sujeto de protección podría presentar un daño irreparable.

Sobre esto, resulta ilustradora la Observación General n. ${ }^{\circ} 14$ de las Naciones Unidas. En ella se ha dicho que el NNA es también una "norma de procedimiento", lo que según su texto implica que: "siempre que se tenga que tomar una decisión que afecte a un niño en concreto (...) el proceso de adopción de decisiones deberá incluir una estimación de las posibles repercusiones (positivas y negativas) de la decisión en el niño o niños interesados". Y agrega que "la justificación de las decisiones debe dejar patente que se ha tenido en cuenta explícitamente ese derecho" (...) "En qué criterios se ha basado la decisión y cómo se han ponderado los intereses del niño frente a otras consideraciones, ya sea se trate de cuestiones normativas, generales o de casos concretos" 58 .

Con lo expresado en este acápite, se han querido disminuir las posibilidades con las que se puede anular una sentencia por el defecto en comento, para dejar solo una (i). Se examinará a continuación.

\subsection{UNA PROPUESTA TEÓRICA: LA RECONDUCCIÓN DE LA CAUSAL DE CASACIÓN}

Aunque no siempre fue así, hoy es axiomático entender que el deber de fundamentación de las resoluciones es absolutamente imprescindible y su omisión constituye un vicio susceptible de invalidación. Si la sentencia no es fundada, producirá el mismo estupor para todo el sistema de justicia, en especial para los justiciables, que si la decisión fuese entregada a un "juego de dados" 59 . Máxime, como se ha pretendido notar hasta ahora, si se tiene en consideración la importancia del derecho tutelado en relación con el sujeto de protección ${ }^{60}$.

Entonces, el foco del problema ya no discurre sobre al examen del derecho de fondo, ni el incumplimiento de un trámite esencial, sino a que su falta de fundamentación sofoca el Derecho y todos sus aditamentos. Lo anterior -la falta de fundamentos en la sentenciasi debe traducirse en un error formal en la tramitación del proceso, a diferencia de lo que estima la Corte Suprema, ha de trasladarse a la causal expresa del artículo 67 b) en relación con el 66 de la ley n. ${ }^{\circ}$ 19.968. Esto es una repetición un tanto más específica a los asuntos de familia de la regla expresada en el numeral cinco del artículo 768 del Código de Procedimiento Civil. Ello, porque lo que ha ocurrido aquí es que la sentencia definitiva se ha dictado sin la fundamentación que le es requerida. En este punto, debe estimarse que en algún sentido la falta de motivos sobre un aspecto de tal relevancia que se irradió a todas las demás justificaciones de la sentencia produce la nulidad de las mismas ${ }^{61}$.

A modo ilustrativo, tratándose del procedimiento de adopción, si el juez no consulta el consentimiento del menor adulto, oblitera directamente lo señalado en el artículo tercero de la ley 19.620. El juez desaplica sencillamente una norma legal. Los supuestos de hecho

\footnotetext{
NaCiones Unidas (2013) p. 4.

ACCATINO (2003) p. 10.

NaCiOnes Unidas (2013) pp. 20 -21.

Atria expone un caso en que la Corte Suprema, por insuficiencia de las razones dadas a conocer por los sentenciadores, entendió la inexistencia de aquellas razones. Atria (2005) p. 323.
} 
de la norma no implican una mayor indagación por parte del ente revisor que el simple análisis de un certificado de nacimiento, en correlación a la omisión y un tipo de procedimiento. La estructura de la ocurrencia del vicio es que se ha desatendido el texto formal de la ley, en los términos que se acostumbra a retratar esta circunstancia para la procedencia de la casación en el fondo ${ }^{62}$. Aunque, según ya se expresó, esta situación obedece a parámetros diversos que los que constituyen el centro de esta investigación.

En el plano teórico la propuesta que se presenta en este parágrafo parece viable. El mandato de la Convención de escuchar al niño no posee cortapisas de ningún tipo. Sobre todo, si se considera su jerarquía normativa. Toda autoridad que deba resolver sobre sus intereses debe tomar en cuenta su opinión en la forma que se ha expuesto en estas líneas. Los jueces que integran los tribunales superiores de justicia no están exentos de ese mandato, con mayor razón cuando no lo han ejecutado los inferiores. Así, podría estimarse que acogida la causal por falta de fundamentos del fallo debería escucharse al menor de todas maneras; pese a que el derecho interno, por la propia naturaleza de la casación, aparentemente no permite esa circunstancia. Esto tendría lugar antes de dictarse la nueva sentencia. Recordando que no se trata en estricto rigor de la apreciación de una prueba.

Pero en la práctica ha de reconocerse que aquello se torna muy complejo. Parece difícil que las Cortes luego de acogida la casación pueda, en mérito de argumentos supralegales, suplir por sí mismas el trámite omitido en primera instancia. El derecho interno posee un peso por sí mismo y por la fuerza de la tradición que no hace posible divisar otra solución que la acostumbrada. Es decir, debe dictarse de inmediato y sin más trámite sentencia de reemplazo. Esto obsta cualquier intención de escuchar a un niño y de paso disipará todo argumento en esa dirección.

\subsection{LA VERTIENTE ADECUADA: EL RECURSO DE APELACIÓN}

Sin perjuicio de lo dicho hasta ahora, la enmienda adecuada de toda situación que pueda gestarse a propósito del DNO debe encontrarse en el recurso de apelación. Por aquel medio, la Corte de Apelaciones posee habilitación legal para inmiscuirse en todos los aspectos del proceso. Particularmente en este punto, tiene la posibilidad de tomar por sí misma la audiencia confidencial omitida. Con ello se asegura uno de los aspectos más relevantes en el ejercicio del derecho por parte de quien debe tutelarlo: la inmediación. Esta constituye la base de un proceso oral ${ }^{63}$. Es aquí donde aquel principio es de tal manera relevante ${ }^{64}$, que todas las normas referentes al DNO apuntan a la estricta necesidad de su cumplimiento. Es el núcleo operativo del derecho. No se comprende cómo podría valorarse la opinión de un niño, si no es precisamente escuchada por aquel quien debe decidir sobre él.

Con lo anterior, no se induce a pensar que se esté frente a una diligencia probatoria $^{65}$, ya que ello puede ser muy discutible. Se precisa que dicha directriz involucra la

\footnotetext{
62 TaVolari (1996) p. 51.

63 Chiovenda (1940) pp. 162 y 163.

64 Así está expresamente declarado por el artículo 9 de la ley 19.968 y desarrollado por el artículo 12 de la misma ley.

65 Como se dice en la introducción, la catalogación de la diligencia no es una cuestión clara y debe ser indagada con profundidad. Los aspectos de su incorporación y rasgos disímiles con los parámetros propios de los
} 
percepción inmediata de todos los aspectos relevantes del proceso que, a la sazón de la oralidad, el juez pueda apreciar. Ello, porque implica "abreviar la distancia, y por consiguiente acercar todo los más posible el juzgador a las partes y a los hechos debatidos" ${ }^{66}$. Como se ha visto en este último orden de ideas, si la inmediación es un vértice en el adecuado ejercicio del derecho, no se ve cómo puede inmiscuirse el juez de grado en aspectos que son del todo fácticos y, a su vez, no le constan por sus propios sentidos.

Puede ocurrir que las Cortes se circunscriban a escuchar el audio de la diligencia o incluso una video grabación. Así aconteció en una jurisprudencia reciente a propósito de un caso donde se debatió el derecho a mantener una relación directa y regular de un padre con sus dos hijos ${ }^{67}$. Si bien, mediante ella en algún punto se logra oír efectivamente a un niño, esta situación no es la deseable, ya que la inmediación que requiere la diligencia no se limita a solo escucharlo, que sería su segunda fase. La primera está relacionada con las decisiones que conforme a los demás antecedentes del proceso y el pulso de la misma declaración dan al juez luces, para seguir con el curso de la diligencia en una u otra dirección. Ello únicamente se puede desarrollar y apreciar in situ. Una cápsula que contenga la diligencia ${ }^{68}$, por muy práctica que parezca, petrifica todos los factores extras que alimentan el trámite y unidirecciona el curso de la entrevista, a lo que el juez de turno fue palpando en la misma.

Además, en el sistema actual de los tribunales de familia, la diligencia se vierte en una grabación de audio, no de video. Ello cercena aún más otro de los acápites de la inmediación, cual es la apreciación de los gestos que revelan emociones de las que se desprenden intenciones o voluntades susceptibles de apreciación. Particularmente, las inconsistencias entre el lenguaje corporal y hablado, que pueden hacer dudar sobre la opinión que se está diciendo a viva voz. Si un niño dice que sí, pero se encoje de hombros y su rostro demuestra tristeza, no se puede arribar indubitadamente a su afirmativa. Incluso, muchas veces se indica al niño que dibuje y sobre esas gráficas se pueden sacar valiosas conclusiones. El consejo técnico, conformado en una buena parte por sicólogos y trabajadores sociales ayuda exitosamente a dicha labor. Por otra parte, en ocasiones existe la imposibilidad de contar con una grabación de audio, cuando lo único que se apreció fue la expresión corporal de un infante. Lo que sucede habitualmente con los menores de 2 años, o aquellos con limi-

medios de prueba generalmente admitidos hacen dudar que sea alguno de ellos, en aquel sentido acostumbrado. Por ejemplo, las partes no tiene la oportunidad de objetar su incorporación y ni siquiera tienen la oportunidad de tomar conocimiento de su contenido, cual es un rasgo esencial de la prueba en el Derecho. Por lo mismo tampoco podrían infringirse mediante la actuación o su falta, las llamadas "leyes reguladoras de la prueba", para analizar la procedencia de la casación en el fondo. Sí, de la forma que sea, el juez debe otorgarle valor, para decidir sobre la cuestión controvertida que suscita el pleito cuyo objeto envuelve los intereses de un niño.

66 Carnelutti (1958) p. 151.

67 R. CON L. (2016).

68 Actualmente se tramita en el Congreso el proyecto de ley que regula entrevistas grabadas en video y otras medidas de resguardo e menores de edad víctimas de delitos sexuales (Boletín 9245-07). Mediante aquel se pretende unificar la audiencia confidencial del niño a un instante video grabado, reutilizable a todas las instancias de persecución penal donde se requiera la asistencia del infante. Lo anterior, como lo indica el proyecto, para evitar la revictimización de los niños. 
taciones de lenguaje ${ }^{69}$. El Comité de los derechos del niño es categórico en afirmar que el derecho del niño no está limitado a su expresión verbal ${ }^{70}$.

Corrobora la productividad del remedio que se plantea en este párrafo el hecho de que algunos tribunales superiores de justicia comienzan a usar el criterio descrito. Así, la Ilustrísima Corte de Apelaciones de Santiago en una disputa de cuidado personal, donde fue omitida la audiencia en el tribunal de primea instancia, ha dicho lo siguiente: "ha procedido esta Corte a disponer como medida para mejor resolver la citación de la niña a fin que hiciera ejercicio del derecho que en tal sentido le corresponde, considerando que de acuerdo a los informes periciales tiene la madurez necesaria para manifestar su parecer, verificándose tal diligencia el día 16 del mes en curso y que tiene especial relevancia para estos juzgadores al momento de resolver (...)"

\section{CONCLUSIONES}

Sin duda que el derecho de los niños, en especial la categoría en referencia amerita una especial atención por los operadores de justicia. Es un derecho esencial, pero aquello no lo ha transformado en un trámite esencial, en los términos establecidos en la ley para la casación. En consecuencia, su omisión no produce la nulidad de aquellas causas donde no acontece. Ello, porque la determinación del hecho que un niño esté en condiciones de formarse un juicio propio para manifestar su opinión confiere una facultad al juez, no una obligación. Los cuerpos normativos donde el derecho se desarrolla establecen condiciones para su ejercicio. Estas -edad y madurez- solo pueden ser conocidas, apreciadas y valoradas por el juez de la instancia. En mérito de ese factor binario, es posible decidir legítimamente no oír a un niño.

Es por esto por lo que no resulta plausible el precedente que ha cristalizado hasta ahora. Porque no se trata de un llamado a conciliación o citación a oír sentencia, que no pueden en ninguna circunstancia dejar de efectuarse cuando son procedentes. No es obligatorio para el juez entrevistar a un niño, como sí son obligatorios los trámites procesales señalados, si a su juicio este no está en condiciones de manifestar su parecer.

Con esa doctrina jurisprudencial, se instiga a la judicatura a escucharlo el cien por ciento de las veces, bajo el apercibimiento de anular lo decidido. Si un infante no fue escuchado por un juez que ha tomado en cuenta que es perjudicial para él, es paradójico obligarlo a efectuar la diligencia. Ello, porque el juez bajo esa presión actuará a sabiendas de lo nocivo que, de acuerdo con las circunstancias, es traerlo a estrados.

Luego, se ha sugerido que la omisión infundada de la diligencia confiere en teoría la posibilidad de anular el fallo, por la causal que es propia a este defecto. Es decir, la establecida en el numeral cinco del artículo 768 del Código de Procedimiento Civil, a saber: la falta de fundamentación de la sentencia. Pero, por las razones vistas, si bien en teoría puede plantearse tal posibilidad, el estado actual de la legislación dificulta su viabilidad práctica.

\footnotetext{
LANSDOWN (2005) p.4.

NACiONES Unidas (2009) p. 9.

G. CON P. (2016).
} 
Lo ideal es que la judicatura en su totalidad comprenda que siempre deberá expresar las razones por las que decide o no escuchar a un niño. Así, no solo cumple el mandato legal, sino que también queda cubierto de la posible nulidad de sus sentencias.

En cualquier evento, lo apropiado será revisar la causa por la vía de la apelación. En este caso las Cortes poseen las competencias necesarias para indagar con plenitud si hubo o no una consideración fáctica por parte del juez de los puntos subjetivos que debió indagar en orden a ejercer o no la adecuada protección del derecho. Cualquiera sea el motivo por el que el juez de primer grado no escuchó al niño, no hay impedimento legal ni factual para que los jueces de tribunales superiores procedan ellos mismos con el trámite. La inmediación y el mandato consignado en el artículo $12 \mathrm{n} .^{\circ} 2$ de la Convención así lo exigen.

El derecho del niño a ser oído es una figura jurídica en construcción. Sus contornos deben ser precisados a través del tiempo. Sus perspectivas actuales deben ser matizadas y corregidas a la luz de la doctrina, de una adecuada interpretación legal y de los necesarios cambios jurisprudenciales que se han propuesto y que se vayan produciendo de acuerdo con las circunstancias.

\section{BIBLIOGRAFÍA CITADA}

Accatino Scagliotti, D. (2003): "La Fundamentación de las sentencias: ¿Un rasgo distintivo de las judicatura moderna?”, Revista de Derecho (Valdivia), vol. XV: pp. 9-35.

Aliste Santos, T. J. (2011): La motivación de las resoluciones judiciales (Barcelona, Marcial Pons).

Atria, F. (2005): "La casación como problema”, Revista de Derecho de la Universidad Adolfo Ibáñez, $\mathrm{N}^{\circ}$ 2: pp. 249 -351.

Belvedere, A. (1994): "Forma", en Belverde A., Guastini R., Zatti P., Zeno V., Iudica G. (edits.), Glossario (Milano, Giuffrè) pp. 148 -158.

Carnelutti, F. (1958): Trattato del processo civile (Napoli, Morano).

Chiarloni, S. (2013): "Ragionevolezza costituzionale e garanzie del processo", Rivista di Diritto Processuale, vol. LXVIII, Nº 3: pp. 521- 540.

Chiovenda, G. (1940): Instituciones de derecho procesal civil (Madrid, Editorial Revista de Derecho Privado).

Chiovenda, G. (1965): Principi di diritto processuale civile (Napoli, Dott. Eugenio Jovene).

Comoglio, L. P., Ferri, C. y Taruffo, M. (2011): Lezioni sul processo civile (Bologna, Il Mulino, segunda edición)

Couso, J. (2006): "El niño como sujeto de derechos y la nueva Justicia de Familia. Interés Superior del Niño. Autonomía progresiva y derecho a ser oído” Disponible en: http:// www.unicef.cl/web/wpcontent/uploads/doc_wp/revista\%20derechos\%203_4.pdf

Denti, V. (1982): Un progetto per la giustizia civile (Bologna, Il Mulino).

Fuentes Maureira, C. y García Odgers, R. (2015): "Entre la opacidad y la reflexión: a propósito de la práctica de la audiencia reservada ante los tribunales de familia", Revista de Derecho de Familia, vol. III, Nº 7: pp. 55-82.

Gometz, G. (2005): La certezza giuridica come prevedibilità (Torino, Giappichelli Editore). 
Greeven, N. (2017): Filiación. Derechos humanos fundamentales y problemas de su actual normativa (Santiago, Librotecnia).

Guastini, R. (2013): Distinguendo ancora (Madrid, Marcial Pons).

Lansdown, G. (2005): “The Evolving Capacities of the Child”. Disponible en: https:// www.unicef-irc.org/publications/384/

Lathrop Gómez, F. (2002): El derecho del niño a ser oído en el nuevo derecho de familia (Santiago, Universidad de Chile).

Luiso, F. (2007): Diritto processuale civile (Milano, Giuffré).

Luzzati, C. (2012): Principi e principi. la genericità nel diritto (Torino, Giappichelli Editore).

MaGno, G. (2001): Il minore come soggetto processuale, commento alla convenzione europea sull'esercizio dei diritti dei fanciulli (Milano, Giuffrè).

Ministerio de Justicia (2013). "Anuario estadístico sobre la justicia de familia”. Disponible en: http://historico.minjusticia.gob.cl/media/2015/04/Anuario-Estadistico-2013-_-Justicia-de-Familia-2013.pdf

Monteleone, G. (2009): Manuale di diritto processuale civile, Tomo I (Milano, Cedam).

Negri, A. (1962): Alle origini del formalismo giuridico (Padova, Università di Padova).

Nieva, J. (2010): El recurso de casación (Santiago, LegalPublishing).

PARKes, A. (2013): Children and International Human Rights Law, the Right of the Child to Be Heard (New York, Routledge).

Ravetllat Ballesté, I., y Pinochet Olave, R. (2015): "El interés superior del niño en el marco de la convención internacional sobre los derechos del niño y su configuración en el derecho civil chileno", Revista Chilena de Derecho, vol XLII, N 3: pp. 903 - 934.

Romero Seguel, A. (2013): El recurso de casación en el fondo civil (Santiago, Thomson Reuters).

Romero Seguel, A., Aguirrezabal Grunstein, M., \& Baraona González, J. (2008): "Revisión crítica de la causal fundante del recurso de casación en el fondo en materia civil”, Ius et Praxis, vol. XIV, $\mathrm{N}^{\circ}$ 1: pp. 225-259.

Sánchez-Eznarriaga, Z. (2011): "El menor en los procesos de familia”, en Gisbert Pomata, M., Adroher Biosca, S., Álvarez Vélez, M., De la Rosa Cortina, J., Serrano Molina, A., Suárez Santos, R., Alcón Yustas, F. y De Montalvo, F. (edits.), Los menores en el proceso judicial (Madrid, Tecnos): pp. 59 - 92.

Schauer, F. (1991): Playing y the Rules (Oxford, Clarendon Law Series).

TARuffo, M. (2005): El vértice ambiguo (Lima, Palestra).

Taruffo, M. (2013): Processo civil comparado. Ensaios (Sao Paulo, Marcial Pons).

Tavolari Oliveros, R. (1996): El recurso de casación y queja (Santiago, Editorial Jurídica Cono Sur).

Thomas, E. W. (2005): The Judicial Process (New York, Cambridge University Press).

Vargas Pavez, M., y Correa Camus, P. (2011): "La voz de los niños en la justicia de familia en Chile", Ius et Praxis, Vol XVII N 1: pp. 177 - 204. 


\section{JURISPRUDENCIA CITADA}

Caso Atala Riffo e hijas vs. Chile. Corte Interamericana de Derechos Humanos. Sentencia de 24 de febrero de 2012. Serie C No. 239, disponible en: http://corteidh.or.cr/ docs/casos/articulos/seriec_239_esp.pdf

A. con T. (2012): Corte de Apelaciones de Valparaíso, 18 de julio de 2012 (relación directa y regular), disponible en: http://www.intranet.pjud/base_documental/

E. CON D. (2015): Corte Suprema, 18 de agosto de 2015 (acción de filiación), disponible en: http://www.intranet.pjud/base_documental/

G. CON P. (2016): Corte de Apelaciones de Santiago, 22 de noviembre de 2016 (relación directa y regular), disponible en: http://www.intranet.pjud/base_documental/

L. CON S. (2011): Corte de Apelaciones de San Miguel, 7 de diciembre de 2011(cuidado personal), disponible en: http://www.intranet.pjud/base_documental/

M. con G. (2016): Corte de Apelaciones de Valdivia, 17 de octubre de 2016 (cuidado personal), disponible en: http://www.intranet.pjud/base_documental/

R. L. G. N. (2009): Corte de Apelaciones de Valdivia, 14 de mayo de 2009 (medida de protección), disponible en: http://www.intranet.pjud/base_documental

R. CON L. (2016): Corte de Apelaciones de Santiago, 11 de abril de 2016 (relación directa y regular), disponible en: http://www.intranet.pjud/base_documental/

R. I. M C. y R. N. M. C. (2011): Corte de Apelaciones de Punta Arenas, 7 de julio de 2011 (medida de protección), disponible en: http://www.intranet.pjud/base_documental/

S. O. T. (2016): Corte de Apelaciones de Santiago, 1 de julio de 2016 (medida de protección), disponible en: http://www.intranet.pjud/base_documental/

\section{NORMAS CITADAS}

Código de Procedimiento Civil chileno (30 de agosto de 1902).

Convenio Europeo sobre el Ejercicio de los Derechos de los Niños, Estrasburgo (25 de enero de 1996).

ACтA 237-2014 (30/12/2014), Auto acordado que regula la implementación de las salas Gesell.

LEY $N^{\circ} 19.968$ (30/08/2004), ley sobre tribunales de familia.

LEY $N^{\circ} 19.947$ (17/05/2004), ley sobre matrimonio civil.

\section{OTRAS FUENTES}

Naciones Unidas, Comité de los derechos del niño "Observación general n ${ }^{\circ} 12$ sobre el derecho del niño a ser escuchado" CRC/C/GC/12 (20 de julio de 2009).

Naciones Unidas, Comité de los derechos del niño “Observación general N 14 sobre el derecho del niño a que su interés superior sea una consideración primordial CRC/C/ GC/14 (29 de mayo de 2013). 